\title{
Lead Specific and Nonspecific Resistance Indices in Adolescents With Bronchial Asthma When Exposed to Vehicle Emissions
}

\author{
Okonenko T.I.* Proshina L.G. Proshin A.V. Antropova G.A. Rumyantsev E.E.
}

Yaroslav-the-Wise Novgorod State University, Veliky Novgorod, Russia

*Corresponding author. Email: tat542@yandex.ru

\begin{abstract}
The paper presents the relationship between air pollution, recorded in Veliky Novgorod, with maximum onetime concentrations of phenol, dust, and nitrogen dioxide and the number of appointments made by adolescents with bronchial asthma to see an allergist. It provides data on the amount of $\mathrm{CD}_{3}{ }^{+}, \mathrm{CD}_{4}{ }^{+}, \mathrm{CD}_{8}{ }^{+}$, $\mathrm{CD}_{3}{ }^{-} \mathrm{CD}_{16} \& \mathrm{CD}_{56}{ }^{+}, \mathrm{CD}_{19}{ }^{+}$, malondialdehyde, and diene conjugates in their blood. During the experiments Wistar rats were exposed to diesel exhaust for two weeks. The authors studied the content of diene conjugates and malondialdehyde in the plasma and erythrocytes of animals on days 3,6 and 9, as well as the dynamics of antioxidant enzymes such as glutathione reductase, glutathione synthetase, glutathione peroxidase in lung tissues. There was a tendency for increased absolute content of $\mathrm{CD}_{3}{ }^{+}$and $\mathrm{CD}_{19}{ }^{+}$, as compared to healthy adolescents ( $\mathrm{p}=0.037$ and $\mathrm{p}=0.039$, respectively). The relative content of $\mathrm{CD}_{8}{ }^{+}$and $\mathrm{CD}_{4}{ }^{+}$tended to decrease ( $\mathrm{p}=0.029$ and 0.031 , respectively). There was an increase in the content of malondialdehyde in the plasma of patients with bronchial asthma $(1.21 \pm 0.02 \mu \mathrm{mol} / \mathrm{ml}, \mathrm{p}<0.001)$ and diene conjugates $(120.56 \pm 52.31 \mathrm{lmh} / \mathrm{lip}$ $\mathrm{p}<0.005)$. The experimental animals had an increased amount of malondialdehyde and diene conjugates in plasma and erythrocytes on the 3rd day. The activity of glutathione reductase, glutathione synthetase, and glutathione peroxidase reduced in the lung tissues at all observation times.
\end{abstract}

Keywords: adolescents, air pollutants, malondialdehyde, diene conjugates, immune system, antioxidant enzymes

\section{INTRODUCTION}

In recent years, researchers have been greatly concerned about steadily increased air pollution and a negative impact of air pollutants on human health [21, 22].

Today, road transport is considered to be the main source of urban pollution [4, 7]. Hazardous substances contained in exhaust gases have a wide range of negative effects on a living system and can cause and exacerbate a significant number of diseases $[12,17]$.

As compared to industrial emissions, exhaust gases containing airborne pollutants pose a greater danger, as they are in the atmosphere right at the level of human respiratory system [9].

Exhaust gas is discharged into the atmosphere together with carbon monoxide, hydrocarbons, nitric oxides, sulfur dioxide, methane, ammonia, soot, and aldehydes. The impact of these air pollutants on the human body is of greatest concern to doctors [24]. Carbon monoxide contained in exhaust fumes prevents oxygen enrichment of the blood, which can cause loss of consciousness in case of significant poisoning. Once deposited onto the respiratory mucous, ozone irritates it, causes cough and impaired lung function [6].
Motor transport is a source of fine aerosols consisting mainly of soot particles. A rise in atmospheric concentrations of $\mathrm{PM}_{10}$, sulfur dioxide and nitric oxides reduces lung functioning [15].

Diesel vehicles emit less $\mathrm{CO}_{2}$ into the atmosphere than their gasoline counterparts, but at the same time they pollute the air with a higher amount of particulate matter (PM), while gasoline engines have lower PM emissions [20].

Nitrous oxides lead to an increase in the specific and nonspecific bronchi activity, whereas nitrogen oxide (II) causes tissue hypoxia [8].

Formaldehyde that has a carcinogenic, irritating effect on the upper respiratory tract also falls within the above adverse factors.

It is reported to have a sensitizing, immunotropic effect on the body. A correlation was established between the rate of formaldehyde and immunoglobulin $\mathrm{E}(\mathrm{IgE})$ in the blood of the target children. With an increase in Blymphocytes and a constant content of T-suppressors, the number of T-lymphocytes, T-helper cells was proved to reduce $[5,25]$.

Phenol is also an air pollutant that, once ingested, has a general toxic resorptive effect, and indirectly affects immune responsiveness [19]. 
Children's health has always been regarded as an indicator of a negative environmental impact on public health at large [23].

The level of morbidity from respiratory diseases among the entire population strongly correlates with the excessive maximum permissible concentration (MPC) of phenol and nitrogen dioxide in the atmosphere. Among children there is a relationship between respiratory morbidity and excess MPC of ammonia and nitrogen dioxide in the air. An average direct correlation was found between respiratory morbidity and excess MPC of ammonia, phenol and dust in the air [3].

Children's health can also grow worse in conditions of low environmental pollution [10].

Airborne pollutants can also have a complex effect on people's ill health, but at present it is not possible to establish safe levels of combined pollutants that do not adversely affect health. Therefore, a study on the effect that low rates of airborne pollutants might have on the human body seems relevant.

Under a prolonged exposure to harmful agents of relatively low intensity, the promotion or prevention of a disease is known to be largely determined by the state of adaptive systems. Protective and adaptive mechanisms that occur in the body at the early pathological stages are developed through the earliest metabolic reactions to take place at the cellular and subcellular levels.

One of the most important mechanisms for maintaining the constancy of the internal environment is redox homeostasis.

An imbalance in lipid peroxidation (LP) and state of antioxidant system (AOS) contributes to the development of oxidative stress, which causes molecular disorders. They lead to the development of lung diseases, which is associated with anatomical and physiological characteristics of the respiratory system [2]. Despite an active study on LP processes, local changes in LP-AOS state under the influence of air toxics show no indication of being adequately covered in the literature. Awareness of pathological processes to arise at the preclinical level of a disease, due to a decline in functional reserves that ensure the body's resistance to harmful environmental factors, proves the priority of studying protective and adaptive mechanisms of the lungs including non-respiratory ones.

The study is aimed at the relationship between asthma exacerbation in adolescents aged 11-17 and the rate of air pollutants in the atmosphere of Veliky Novgorod - a region of relative sanitary and epidemiological well-being. It provides a rationale for LP-AOS disturbances at the systemic and local levels in experimental animals under the influence of diesel exhausts.

\section{METHODS AND MATERIALS}

The paper highlights the relationship between the number of doctor's appointments made by the children of different ages with exacerbated bronchial asthma (BA) and the rate of airborne pollutants in the air. The incidence of outpatient visits was studied daily based on a number of appointment confirmations recorded during 2015. The content of dust, phenol, formaldehyde, nitrogen dioxide, ammonia, and carbon monoxide in the air was determined during this period by the Novgorod Regional Center for Hydrometeorology (NRCHM).

Twenty patients with exacerbated atopic asthma aged 11 to 17 years were involved in a medical check-up. There were 14 girls and 6 boys. Sixteen patients had a mild BA degree, four - an average degree of the disease. The control group consisted of 10 healthy adolescents from Veliky Novgorod.

Peripheral blood was sampled by intravenous puncture in heparin-added tubes. A number of lymphocytes labeled with expression tags $\mathrm{CD}_{3}{ }^{+}, \mathrm{CD}_{4}{ }^{+}, \mathrm{CD}_{8}{ }^{+}, \mathrm{CD}_{3}{ }^{-} \mathrm{CD}_{16}$ \& $\mathrm{CD}_{56}{ }^{+}, \mathrm{CD}_{19}{ }^{+}$was determined using monoclonal antibodies (mAbs) against the respective antigens (CD) (an IMK Plus kit by Becton Dickinson, USA). For this, the cells were incubated with mAbs against CD monoclonal antibodiesFITC and -PE. The samples were analyzed using a laser flow cytofluorimeter with the Simul-Set software (Becton Dickinson) for data analysis.

Diene conjugates in blood plasma were determined by Gavrilov method (Gavrilov et al.) following the extraction of lipids with a heptane:isopropyl mixture [1]. The content of malondialdehyde (MDA) in the fraction of TBAreactive substances was determined by the reaction with thiobarbituric acid [11].

Wistar rats were employed to conduct experimental studies in accordance with the Guidelines for the protection and welfare of animals used for scientific purposes, outlined in the Directive 2010/63 / EU, 2010, Guidelines for the maintenance and use of laboratory animals (FELASA, 2010), and "Laboratory animals" (Regulations and Guidelines, Russian Academy of Medical Sciences, Moscow, 2003). All experiments were performed in conformity with Order No. $199 \mathrm{n}$ of the Ministry of Health of the Russian Federation "On approval of the principles of Good Laboratory Practice" dated April 1, 2016, and Guide for the Care and Use of Laboratory Animals (NAP, 2011). The animals were decapitated under mild ether anesthesia.

During the experiment, 100 sexually mature Wistar male rats were divided into 2 equal groups. The first (control) group was composed of intact animals. The second (target) group involved experimental animals that were exposed to exhaust emissions for two weeks in chambers with a capacity of 2001 . Diesel exhausts were supplied into the chambers on working days for 6 hours. The gas concentration in the chambers was 6 MPC with a constant determination of the main components.

Biochemical blood and tissue analysis was carried out in experimental animals. The content of primary and secondary LP products (diene conjugates and malondialdehyde) in the plasma and erythrocytes of animals was examined on days 3,6 and 9. Meanwhile, the dynamics of antioxidant enzymes, including glutathione reductase, glutathione synthetase, and glutathione peroxidase, was evaluated in the lung tissues. These enzymes form a glutathione-dependent antioxidant body resistance system. Glutathione peroxidase activity was 
measured using the standard Paglia and Valentine (1967) method modified by V.Z. Lankin (1981).

Glutathione S-transferase activity in the lung tissue of the animals was determined by the formation of glutathione conjugates with 1-chloro-2,4-dinitrobenzene (Keen, Yakoby, 1978).

Glutathione reductase (GSR) activity was detected by the rate of NADPH decrease due to the reduction of oxidized glutathione during the incubation at $30^{\circ} \mathrm{C}$ (Pinto and Bartley, 1969).

All glutathione-dependent enzymes were studied in a thermostatic 9-channel cell at a wavelength of $340 \mathrm{~nm}$ using a FP-901 Labsystems Oy chemical analyzer (Finland). The activity of the target antioxidant enzymes was expressed in units of activity per $1 \mathrm{mg}$ of protein. Protein was determined through the microbiuret method.

Statistical processing was based on the Statistika 6.0 program using the Student's $t$-test.

\section{RESULTS}

Akron JSC, Novgorod TPP, Teploenergo MUE, and motor vehicles traditionally make the largest impact on air pollution in Veliky Novgorod. The impact of traffic on the total emissions amounted to about $69 \%$.

In 2015 the extent of air pollution in Veliky Novgorod was high. The Air Pollution Index (API) was equal to 5 . The main impact on air pollution in the city was made by copper (API - 2.0), ammonia (API - 1.3), benzapilene (API - 2.0), phenol (API - 0.9), ammonia (API - 0.9), suspended substances (API - 0.6), nitrogen oxide (API 0.6 ) and nitrogen dioxide (API - 0.5)

The average annual concentration of suspended substances in the city was 0.4 MPC, the maximum onetime concentration was 3.8 MPC. The level of dust in the city was high (SI value $-3.8, \mathrm{MF}-1.4 \%$ ).

Sulfur dioxide was not found in the air samples.

Table 1 Correlation between the number of allergologist appointments made by ba adolescents (n), aged 11-17, and air pollution in 2015

\begin{tabular}{|c|c|c|c|c|c|c|}
\hline Pollutant & & $\begin{array}{c}\text { Phenol } \\
\max \end{array}$ & $\begin{array}{c}\text { Ammonia, } \\
\text { max }\end{array}$ & $\begin{array}{l}\text { Formaldehyde, } \\
\max \end{array}$ & $\begin{array}{l}\mathrm{NO}_{2}, \\
\max \end{array}$ & Dust, max \\
\hline Month & Number of people & $\mathbf{p}$ & $\mathbf{p}$ & $\mathbf{p}$ & $\mathbf{p}$ & $\mathbf{p}$ \\
\hline $\begin{array}{l}\text { December - } \\
\text { February }\end{array}$ & 92 & 0.38 & 0.29 & 0.43 & 0.21 & 0.12 \\
\hline March - May & 87 & 0.48 & 0.47 & 0.43 & 0.29 & $0.58^{*}$ \\
\hline June - August & 64 & $0.54^{*}$ & $0.61^{*}$ & $0.53^{*}$ & $0.76^{* *}$ & $0.85^{* * *}$ \\
\hline $\begin{array}{l}\text { September - } \\
\text { November }\end{array}$ & 85 & $0.52^{*}$ & $0.54^{*}$ & 0.36 & 0.47 & $0.55^{*}$ \\
\hline
\end{tabular}

Note: $* \mathrm{p}<0.05 ; * * \mathrm{p}<0.001$
The average concentration of nitrogen dioxide in the city was $0.5 \mathrm{MPC}$, the maximum one-time concentration was 2.9 MPC. The level of air pollution with nitrogen dioxide was high (SI - 2.9).

The average annual concentration of carbon monoxide in the city was $0.2 \mathrm{MPC}$, the maximum one-time concentration was 1.2 MPC. In 2015, air pollution with carbon monoxide was described as low (SI - 1.2).

The annual average phenol concentration was $0.2 \mathrm{MPC}$ $(0.001 \mathrm{mg} / \mathrm{m} 3)$, in accordance with the daily average MPC for phenol concentrations approved in 2015. The maximum concentration of phenol repeatedly exceeded the MPC by 2.6 times. The level of air pollution with phenol was characterized as high (SI - 2.6, MF - $1.5 \%$ ).

The average concentration of ammonia in the city was 1.3 MPC, whereas the maximum concentration was 3.4 MPC. During the year, the MPC increased. The extent of air pollution was high (SI - 3.4, MF - 3.9\%).

The extent of air pollution in Staraya Russa can be characterized as low (API - 0.2). Sulfur dioxide was not detected in the air samples. The annual average and maximum one-time concentrations carbon monoxide and nitrogen dioxide did not exceed the specified MPC. The extent of air pollution by these impurities was low.

The relationship between asthma exacerbations in adolescents of Veliky Novgorod and the extent of air pollution with maximum one-time concentrations of major air pollutants is shown in Table 1 . of patients with asthma exacerbations and the content of one-time concentrations of phenol, ammonia, nitrogen dioxide and dust in the spring, summer and autumn.

The pattern of peripheral lymphocyte populations and subpopulations in patients with bronchial asthma and individuals in the control group of Veliky Novgorod are shown in Table 2.
A strong correlation was obvious between the number 
Table 2 Indices of immuno-phenotyping through flow cytometry in healthy and asthma patients aged 11-17 (m $\pm \mathrm{m})$

\begin{tabular}{|l|c|c|}
\hline \multicolumn{1}{|c|}{ Index } & Control group $(\mathbf{n = 1 0})$ & BA (n=20) \\
\hline Peripheral blood lymphocyte, thous. & $6299 \pm 190$ & $8488.5 \pm 254.6^{*}$ \\
\hline $\mathrm{CD}_{3}$, absolute WBC & $1906 \pm 151.1$ & $2148 \pm 163.1$ \\
\hline $\mathrm{CD}_{3}, \%$ & $66.8 \pm 1.28$ & $70.0 \pm 1.35$ \\
\hline $\mathrm{CD}_{19} \%$ & $13.9 \pm 0.34$ & $15.3 \pm 0.25$ \\
\hline $\mathrm{CD}_{19}$, absolute WBC & $306.84 \pm 29.13$ & $311.5 \pm 29.7$ \\
\hline $\mathrm{CD}_{4}, \%$ & $36.8 \pm 1.49$ & $35.0 \pm 1.3$ \\
\hline $\mathrm{CD}_{8} \%$ & $28.0 \pm 1.61$ & $27.1 \pm 1.46$ \\
\hline $\mathrm{CD}_{3}{ }^{-} \mathrm{CD}_{16} \& \mathrm{CD}_{56}{ }^{+} \%$ & $14.6 \pm 0.1$ & $14.8 \pm 0.1$ \\
\hline
\end{tabular}

Note: ${ }^{*} \mathrm{p}<0.05$

In the study, the BA patients, compared with healthy adolescents, had a much higher rate of blood leukocytes, which is the response to inflammation. There was a tendency for increased absolute number of T-lymphocytes of the $\mathrm{CD}_{3}{ }^{+}$phenotype and B-lymphocytes $\left(\mathrm{CD}_{19}{ }^{+}\right.$ phenotype) compared to the healthy adolescents. However, there was no statistically significant difference $(\mathrm{p}=0.037$ vs. $\mathrm{p}=0.039)$. The relative content of cytotoxic lymphocytes $\left(\mathrm{CD}_{8}{ }^{+}\right)$and $\mathrm{CD}_{4}{ }^{+}$(T-helpers) tended to decrease ( $\mathrm{p}=0.029$ vs. 0.031 ).

The LP violations lead to excessive accumulation of free radicals, which alter the permeability, structure, functions of biomembranes and the functioning of the immune system.

The content of malondialdehyde (MDA) in the plasma of relatively healthy adolescents in Veliky Novgorod was significantly lower compared to BA patients $(1.21 \pm 0.02$ $\mu \mathrm{mol} / \mathrm{ml}$ and $1.06 \pm 001, \mu \mathrm{mol} / \mathrm{ml}$, respectively, $\mathrm{p}<0.001)$.

The content of diene conjugates (DC) in the plasma of the patients with bronchial asthma was $120.56 \pm 52.31$ $1 \mathrm{mh} / \mathrm{lip}$, while relatively healthy adolescents in Veliky Novgorod had 76.1 $\pm 40.32 \mathrm{p}<0.005$.

A study on LP violations in the plasma and red blood cells of experimental animals demonstrated an increase in primary and secondary LP products (DC and MDA) on the 3rd day, which reflected the host response to airpollutants (Fig. 1, 2).

The DC indices went down to normal values by the 6th day and again increased on day 9 , which can probably be attributable to a repeated impact of diesel exhausts on the animals (Fig. 1).

As for the content of malondialdehyde in the plasma and red blood cells, it gradually increased by the 7th day and then decreased by the 9th day, without reaching normal values.

The AOS violations in the lung tissue were studied based on a glutathionine-dependent system of experimental animals.

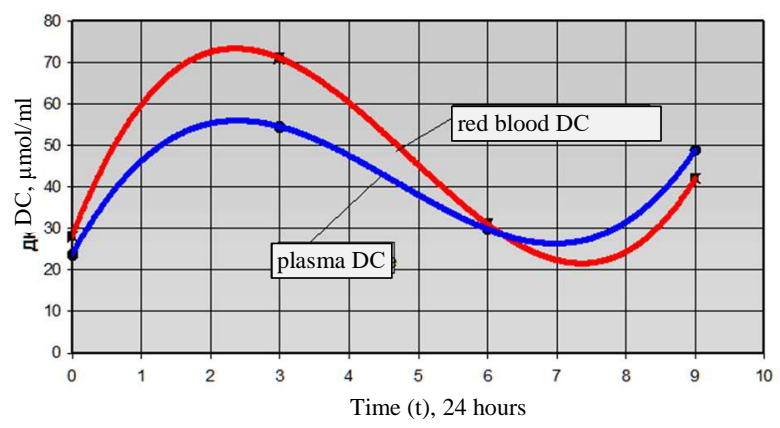

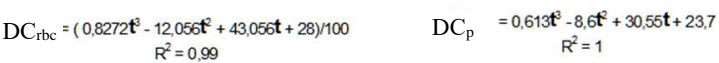

Figure 1 Dynamics of diene conjugates (DC) in red blood cells and blood plasma of experimental animals

A persistent decrease in the activity of GSR, GSS, and GPx in the lung tissue of animals in the experimental group was observed at all stages of the study (Fig. 3).

No LP-AOS changes were detected in the control group of animals.

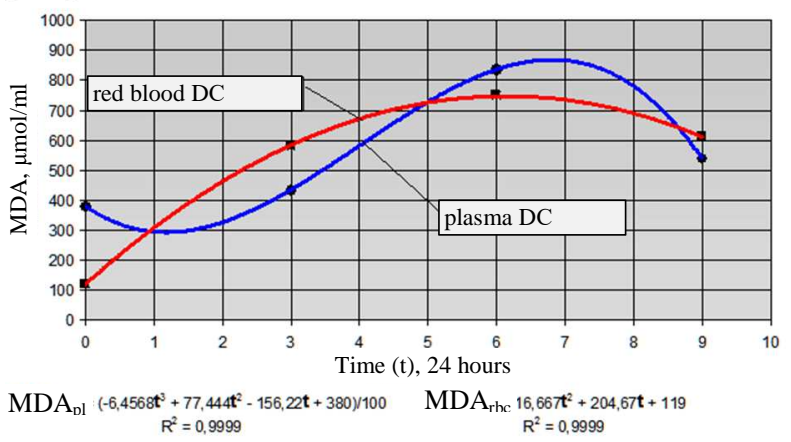

Figure 2 Dynamics of malondialdehyde in red blood cells and blood plasma 
GSR, GSS, GPx

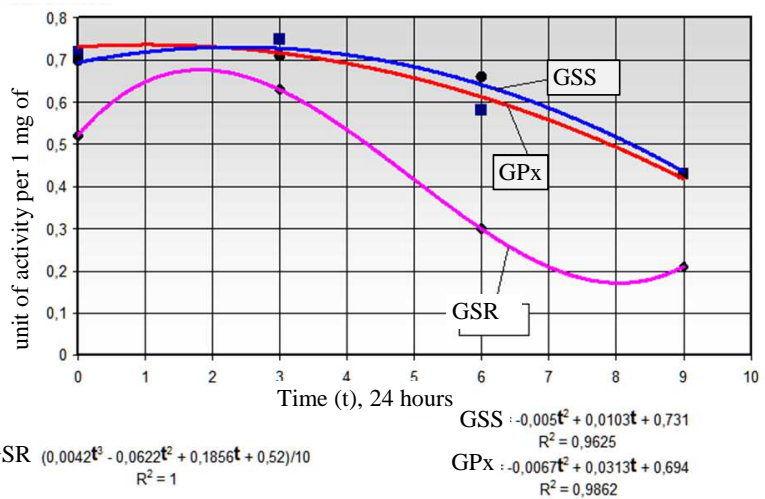

Figure 3 Dynamics of antioxidant enzymes (GSR glutathione reductase, GSS - glutathione synthetase, and GPx - glutathione peroxidase) in the lung tissue

\section{DISCUSSION}

The findings on the relationship between asthma exacerbations in adolescents aged 11-17 and the rate of airborne pollutants confirm some other literature data. The study on the impact of maximum one-time concentrations of airborne pollutants on the occurrence and distribution of asthma among the residents showed a predominant effect of formaldehyde, nitrogen oxide (IV), sulfur oxide (IV), carbon monoxide (II), suspended solids, and phenol. A linear relationship occurred between the primary asthma rates and single concentrations of nitrogen oxide (IV) $(\mathrm{r}=0.79, \mathrm{p}>0.05)$, phenol $(\mathrm{r}=0.76, \mathrm{p}>0.05)$ and dust $(r=0.72, p>0.05)$, contents of nitrogen oxide (IV) $(r=0.72$, $\mathrm{p}>0.05)$, phenol $(\mathrm{r}=0.66, \mathrm{p}>0.05)$ and dust particles $(r=0.60, p>0.05)[13]$.

Immune depletions in patients with bronchial asthma most often relate to a T-link. An allergic inflammation stems from the imbalance in the production of cytokines by type 1 T-helpers (Th1) and type 2 T-helpers (Th2) [14]. BA-related immunodeficiency is attributed to a decrease in the number of T-lymphocytes, especially T-helpers. The studies delineate multidirectional changes, i.e. the increased T-lymphocytes in BA patients and reduced content of T-helper cells.

The content of diene conjugates and malondialdehyde in the patients with asthma exacerbations increased, which may be due to the effect of air pollutants and the inflammatory process.

The resulting morphological manifestations and biochemical data indicate a significant contribution of redox homeostasis disorders to the structural respiratory pathogenesis. Air pollutants are proved to cause direct cell damage [16, 18], which leads to an LP-AOS violation detected in plasma, red blood cells, and lung tissues of experimental animals.

The studies show that in modern conditions, adolescent diets must necessarily contain foods rich in antioxidants (honey, lettuce, carrots, etc.)

\section{CONCLUSIONS}

The authors establish some strong correlations between BA exacerbations in adolescents aged 11-17 and one-time concentrations of phenol, ammonia, nitrogen dioxide and dust in the atmosphere of Veliky Novgorod. The content of diene conjugates and malondialdehyde was increased in the blood of BA adolescents. Besides, there was an imbalance in the T-lymphocyte system. Experimental animals also showed abnormalities in the LP-AOS state. There was an increased content of malondialdehyde and diene conjugates in plasma and erythrocytes and a reduction in the activity of enzymes in the glutathionedependent system in the lung tissue. Such violations are the rationale for enriching the diet with products rich in antioxidants.

\section{CONFLICT OF INTEREST}

The authors declare that there is no need to disclose financial support or conflict of interest regarding the publication of this paper. All authors made an equivalent contribution to the preparation of the paper.

\section{REFERENCES}

[1] V.B. Gavrilov, A.R. Gavrilova, N.F. Khmara, Measurement of diene conjugates in blood plasma using the UV absorption of heptane and isopropanol extracts, Laboratornoe Delo 2 (1988) 60-64.

[2] T.A. Gvozdenko, I.N. Simonova, M.V. Antonyuk et al., On the question of pathogenetic markers of ecologically related respiratory diseases, Bull. Physiol. and Pathol. of Respirat. 62 (2016) 8-15. DOI: 10.12737 / 23112

[3] R.A. Golikov, D.V. Surzhikov, V.V. Kislitsyna, V.A. Shtaiger, Influence of environmental pollution to the health of the population (review of literature), Sci. Rev. Med. sci. 5 (2017) 20-31.

[4] On the condition and protection of the natural environment in the Russian Federation in 2015, State report, NIA-Priroda, Moscow, 2016, 639 p.

[5] N.V. Zaitseva, T.S. Ulanova, O.V. Dolgikh, T.V. Karnazhitskaya, Rationale for maximum inactive concentration of formaldehyde in the blood of children living in territories with different anthropogenic stres", Perm Med. J. 27(1) (2010) 101-104.

[6] L.I. Katashinskaya, N.E. Suppes, Analysis of sources of air pollution in the city of Ishim and the effect of chemical air pollution on public health, Izv. of Samara Sci. Center of the Russ. Acad. of Sci. 18(2) (2016) 697-701.

[7] I.V. May, S.V. Klein, Risk analysis on public health from the effects of vehicle emissions and ways to 
reduce it, Izv. of Samara Sci. Center of the Russ. Acad. of Sci. 13(1) (2011) 1895-1901.

[8] N.V. Ovsyannikov, N.V. Bagisheva, Influence of external risk factors on the incidence of COPD and bronchial asthma in the south of Western Siberia, Atmosphere. Pulmonol. and Allergol. 2 (2007) 54-58.

[9] Yu.A. Rakhmanin, S.I. Ivanov, S.M. Novikov et al. Actual problems of complex hygienic characteristics of the urban environmental factors and their impact on public health, Modern problems of urban hygiene, methodology and solutions: plenum materials, 2006, pp. 8-18.

[10] Russian Statistical Yearbook, vol. 2017.

[11] I.D. Stal'naya, G.G. Garishvili, Contemporary methods in biochemistry, Mediysina, Moscow, 1977, $240 \mathrm{p}$.

[12] N.V. Stepanova, N.V. Svyatova, I.Kh. Sabirova, A.V. Kosov, Assessment of risk to human health from air pollution by motor vehicle emissions, Funda. Issled. 10 (2014) 1185-1190.

[13] M.A. Shcherbakova, Effect of air pollution on incidence of bronchial asthma among adult urban population, Vestnik VDU 2(95) (2017) 40-48.

[14] F. Annunziato, S. Romagnani, Heterogeneity of human effector CD4+ Tcells Arthritis Res, Ther 11(6) (2009) 257-264.

[15] U.A. Ackermann-Liebrich et al., Lung function and long term exposure to air pollutants in Switzerland. Study on Air Pollution and Lung Diseases in Adults (SAPALDIA), Team Am. J. Respir. Crit. Care Med. 155 (1997) 122-129.

[16] H. Bayram, F. Fakili, B. Gögebakan et al., Effect of serum on diesel exhaust particles (DEP)-induced apoptosis of airway epithelial cells in vitro, Toxicol. Lett. 218 (2013) 215-223.
[17] R.D. Brook et al., Particulate matter air pollution and cardiovascular disease: An update to the scientific statement from the American Heart Association, Circulation 121(21) (2010) 2331-2378.

[18] L. Cecchi, G. D’Amato, I. Annesi-Maesano, Climate Vulnerability: Understanding and addressing threats to essential resources, Elsevier Inc., Academic Press, 2013, pp. 105-113.

[19] M. Lippmann (ed.), Environmental toxicants: human exposures and their health effects, 3rd ed., John Wiley \& Sons, Hoboken, 2009, 1167 p.

[20] N. Kojima, A. Tokai, T. Nakakubo, Yu. Nagata, Policy evaluation of vehicle exhaust standards in Japan from 1995 to 2005 based on two human health risk indices for air pollution and global warming, Environ. Syst. and Decisions 36(3) (2016) 229-238.

[21] I. Negi, F. Tsow, K. Tanwar, L. Zhang et al., Novel monitor paradigm for real time exposure assessment, J. of Exposure Sci. and Environ. Epidemiol. 21(4) (2011) 419-426.

[22] A.N. Skouloudis, P. Kassomenos, Combining environment and health information systems for the assessment of atmospheric pollution on human health, Sci. Total. Environ. 488-489 (2014) 362-368.

[23] R. Sram, Health impact of air pollution to children, Int. J. of Hygiene and Environ. Health 216(5) (2013) 533-540.

[24] Ambient (outdoor) air quality and health. Fact sheet 313 (2014), World Health Organization.

[25] X. Ye, W. Yan, H. Xie et al., Cytogenetic analysis of nasal mucosa cells and lymphocytes from high level long-term formaldehyde exposed workers and lowlevel short-term exposed waiters, Mutat. Res. 588(1) (2005) 22-27. 